\title{
CORRIGENDUM
}

\section{Dendritic cell vaccination for cancer therapy}

Frank O Nestle

Correction to: Oncogene (2000) 19, 6673-6679.

Following publication of the above paper, the author has identified errors in Table 1 . The correct version of Table 1 is reproduced below.

Table 1 Summary of published trials in DC vaccination (for details see text)

\begin{tabular}{|c|c|c|c|c|c|c|}
\hline Investigator & Tumor & Source & Antigen & Route & $\begin{array}{l}\text { Tu antigen } \\
\text { specific immune } \\
\text { response }\end{array}$ & $\begin{array}{l}\text { Objective } \\
\text { clinical } \\
\text { response }\end{array}$ \\
\hline Nestle, Schadendorf & Melanoma & Monocytes & $\begin{array}{c}\text { MelanA, } \\
\text { gp100, } \\
\text { tyrosinase, } \\
\text { Tulys }\end{array}$ & Intranodal & yes & yes \\
\hline Lotze & Melanoma & Monocytes & $\begin{array}{l}\text { MelanA, } \\
\text { gp100, } \\
\text { tyrosinase }\end{array}$ & i.v. & no & yes \\
\hline Panelli, Marincola & Melanoma & Monocytes & $\begin{array}{l}\text { MelanA, } \\
\text { gp100 }\end{array}$ & i.v. & yes & yes \\
\hline Thurner, Schuler & Melanoma & Monocytes & MAGE-3 & i.d., i.v. & yes & no \\
\hline Mackensen & Melanoma & CD34 & $\begin{array}{c}\text { MelanA, } \\
\text { gp100, } \\
\text { tyrosinase }\end{array}$ & i.v. & yes & no \\
\hline Höltl, Thurnher & $\mathrm{RCC}$ & Monocytes & Tulys & i.v. & yes & no \\
\hline Levy, Engleman & Lymphoma & $\begin{array}{l}\text { DC blood } \\
\text { precursors }\end{array}$ & idiotype & i.v. & yes & yes \\
\hline Murphy, Salgaller & Prostate & Monocytes & PSMA & i.v. & yes & yes \\
\hline Burch, Vuk-Pavlovic & Prostate & $\begin{array}{l}\text { DC blood } \\
\text { precursors }\end{array}$ & $\begin{array}{l}\text { PAP-GMCSF } \\
\text { fusion protein }\end{array}$ & i.v. & yes & yes \\
\hline Morse, Lyerly & Various & Monocytes & CEA & i.v. & no & no \\
\hline
\end{tabular}

Tulys $=$ tumor lysate, $\mathrm{PAP}=$ prostatic acid phosphatase 